\title{
Blockade of MDM2 with inactive Cas9 prevents epithelial to mesenchymal transition in retinal pigment epithelial cells
}

\author{
Bing Liu, $\mathrm{Lu}^{1,2}$ Jingyuan Song ${ }^{1,3} \cdot$ Haote $\mathrm{Han}^{1,4} \cdot \mathrm{Zhengping} \mathrm{Hu}^{1} \cdot \mathrm{Na} \mathrm{Chen}^{1,5} \cdot \mathrm{Jing}^{\mathrm{C}} \mathrm{Cu}^{6} \cdot$ Joanne Aiko Matsubara$^{6} \cdot$ \\ Jingxiang Zhong ${ }^{2} \cdot$ Hetian Lei ${ }^{1}$
}

Received: 26 April 2019 / Revised: 8 July 2019 / Accepted: 10 July 2019 / Published online: 22 August 2019

(c) United States \& Canadian Academy of Pathology 2019

\begin{abstract}
Epithelial to mesenchymal transition (EMT) plays an important role in the pathogenesis of proliferative vitreoretinopathy (PVR). We aimed to demonstrate the role of mouse double minute 2 (MDM2) in transforming growth factor-beta 2 (TGF$\beta 2$ )-induced EMT in human retinal pigment epithelial cells (RPEs). Immunofluorescence was used to assess MDM2 expression in epiretinal membranes (ERMs) from patients with PVR. A single guide (sg)RNA targeting the second promoter of MDM2 was cloned into a mutant lentiviral Clustered Regularly Interspaced Short Palindromic Repeats (lentiCRISPR) v2 (D10A and H840A) vector for expressing nuclease dead Cas9 (dCas9)/MDM2-sgRNA in RPEs. In addition, MDM2-sgRNA was also cloned into a pLV-sgRNA-dCas9-Kruppel associated box (KRAB) vector for expressing dCas9 fused with a transcriptional repressor KRAB/MDM2-sgRNA. TGF- $\beta 2$-induced expression of MDM2 and EMT biomarkers were assessed by quantitative polymerase chain reaction (q-PCR), western blot, or immunofluorescence. Wound-healing and proliferation assays were used to evaluate the role of MDM2 in TGF- $\beta 2$-induced responses in RPEs. As a result, we found that MDM2 was expressed obviously in ERMs, and that TGF- $\beta 2$-induced expression of MDM2 and EMT biomarkers Fibronectin, $\mathrm{N}$-cadherin and Vimentin in RPEs. Importantly, we discovered that the dCas9/MDM2-sgRNA blocked TGF- $\beta 2$-induced expression of MDM2 and the EMT biomarkers without affecting their basal expression, whereas the dCas9-KRAB/MDM2sgRNA suppressed basal MDM2 expression in RPEs. These cells could not be maintained continuously because their viability was greatly reduced. Next, we found that Nutlin-3, a small molecule blocking the interaction of MDM2 with p53, inhibited TGF- $\beta 2$-induced expression of Fibronectin and N-cadherin but not Vimentin in RPEs, indicating that MDM2 functions in both p53-dependent and -independent pathways. Finally, our experimental data demonstrated that dCas9/ $M D M 2$-sgRNA suppressed TGF- $\beta 2$-dependent cell proliferation and migration without disturbing the unstimulated basal activity. In conclusion, the CRISPR/dCas9 capability for blocking TGF- $\beta 2$-induced expression of MDM2 and EMT biomarkers can be exploited for a therapeutic approach to PVR.
\end{abstract}

\section{Introduction}

Proliferative vitreoretinopathy (PVR) is vision-threatening ocular fundus complication, characterized by formation and

Hetian Lei

Hetian_lei@meei.harvard.edu

1 Schepens Eye Research Institute of Massachusetts Eye and Ear, Department of Ophthalmology, Harvard Medical School, Boston, MA 02114, USA

2 Department of Ophthalmology, The First Affiliated Hospital of Jinan University, 510632 Guangzhou, China

3 Institute of Medicinal Plant Development, Chinese Academy of contraction of fibrotic membranes in the vitreous cavity, and epiretinal and subretinal spaces $[1,2]$. It can occur in longterm primary retinal detachment $(\mathrm{RD})$ or open-globe injury $[2,3]$. PVR is primary reason for re-detachment of retinas

Medical Sciences \& Peking Union Medical College, 100193 Beijing, China

4 Department of Biomedical Engineering, Zhejiang University, 310027 Hangzhou, China

5 Department of Ophthalmology, Renji Hospital School of Medicine, Shanghai Jiaotong University, 200127 Shanghai, China

6 The University of British Columbia, Vancouver, BC V5Z 3N9, Canada 
following correction of RD surgery, and develops in $~ 8-10 \%$ of postoperative patients [4-6]. A surgical strategy is still the most important treatment for PVR. Although great advances have been achieved in vitreoretinal surgical techniques in the past 20 years, the postoperative incidences of PVR still have not declined [7-9]. Therefore, novel medications targeting the specific pathogenesis are highly anticipated for more effective prevention and treatment of PVR.

Retinal pigment epithelial cells (RPEs) comprise the majority cell components of the fibrotic membranes in PVR patients [10]. Under the stimulation of growth factors and cytokines such as transforming growth factor-beta 2 (TGF$\beta 2$ ), epidermal growth factor (EGF), fibroblast growth factor 2 (FGF-2), platelet-derived growth factor (PDGF), and tumor necrosis factor-alpha (TNF- $\alpha)$ in vitreous, RPEs undergo epithelial to mesenchymal transition (EMT), one of the key contributors in the development of PVR [11, 12]. Subsequently, RPEs gain an enhanced ability to proliferate and migrate, and faciliate to form fibrotic membranes.

EMT was originally studied in many tumor types; therefore, some tumor-related molecular mechanisms have been widely explored for their relationship to EMT [13-15]. Mouse double minute 2 (MDM2) is an oncogene protein acting as an E3-ubiquitin ligase of the p53 tumor suppressor $[16,17]$, and plays an important role in EMT in cancer biology through both p53-dependent and -independent pathways [18-21]. However, the role of MDM2 in EMT related to the pathogenesis of PVR remains elusive. There are two promoters in the MDM2 gene. The first promoter (P1) is considered the housekeeping promoter, while the second promoter ( $\mathrm{P} 2)$, located in intron 1, can be activated by a variety of transcription factors including the small mothers against decapentaplegic (Smad) complex [22] and specificity protein (Sp)1 [23] in response to various stimuli (e.g., TGF- $\beta$ ). Increased MDM2 expression is associated with risk of both cancer and PVR from RD, due to the elevated affinity for Sp1 with the $309 \mathrm{G}$ allele of singlenucleotide polymorphism (SNP) (rs2279744) in P2 [5, 23]. Specifically, a change from a $\mathrm{T}$ to $\mathrm{G}$ allele in the MDM2 SNP309 in primary human RPEs enhances PVR potential in vivo and in vitro $[24,25]$. Therefore, suppression of P2driven MDM2 expression to prevent PVR pathogenesis appears to be an attractive strategy.

The technology of clustered regular interspaced short palindromic repeats (CRISPR)/CRISPR-associated protein (Cas)9 is a powerful genetic-editing tool with high specificity for targeting eukaryotic genomes [26, 27]. In addition, a nuclease dead Cas9 (dCas9) with two mutations (D10A, H840A) can be harnessed for the interference of gene expression by blocking transcriptional elongation, RNA polymerase, or transcription factor binding. Under the guidance of a single guide (sg)RNA, this dCas9 can bind to a specific promoter without causing a DNA break for suppressing gene expression [28, 29]. Our pilot experiments indicated that suppression of MDM2 by short-hairpin RNA greatly reduced cell viability probably due to an increased p53 level; therefore, we explored if dCas9 could serve as an alternative approach. To accomplish this goal, dCas9 guided by an MDM2-sgRNA targeting P2 was applied to suppress MDM2 expression induced by a variety of vitreal factors (e.g., TGF- $\beta 2$ ). In addition, a transcriptional repressor named Kruppel associated box (KRAB) domain linked to dCas9 silences the noncoding RNAs more efficiently than does dCas9 alone [30]. Thus, dCas9-KRAB with the MDM2-sgRNA was also transduced into cells for comparing the efficacy of an MDM2 blockade. Overall, in this report we examined the role of MDM2 in PVR pathogenesis in vitro using CRISPR/dCas9 system, further exploring a potential therapeutic approach to PVR.

\section{Materials and methods}

\section{Major reagents}

TGF- $\beta 2$ and TNF- $\alpha$ were purchased from R\&D Systems (Minneapolis, MN, USA). EGF and FGF-2 were obtained from Peprotech, Inc (Rocky Hill, NJ, USA). Nutlin-3 was purchased from Cayman Chemical (Ann Arbor, Michigan, USA). Antibodies against N-cadherin, Vimentin, Cytokeratin (Catalog \#4545), and MDM2 were purchased from Cell Signaling Technology (Danvers, MA, USA). The antibody against Fibronectin was from Abcam (Cambridge, MA, USA). Antibodies against $\beta$-actin and p53 were purchased from Santa Cruz Biotechnology (Santa Cruz, CA, USA). Secondary antibodies of IRDye 800CW goat anti-rabbit IgG and IRDye 680RD goat anti-mouse IgG were obtained from Li-cor Biotechnology (Lincoln, NE, USA). Secondary antibodies of DyLight 549 goat anti-rabbit and DyLight 488 anti-mouse IgG were purchased from Vector Lab (Burlingame, CA, USA).

\section{Epiretinal membrane (ERM) from PVR patients}

ERMs were harvested from PVR patients in Vancouver Hospital (British Columbia, Canada). All cases included were Grade C PVR (1983 Retinal Society classification) and the surgeries were conducted by one senior ophthalmologist. The University of British Columbia Clinical Research Ethics Board approved the study protocol. Its policies complied with Tri Council Policy and Good Clinical Practice Guidelines, which originated with the ethical principles in the Declaration of Helsinki. Written informed consent was obtained from all patients [25].

After being harvested, ERMs were set in Optimal Cutting Temperature compound (Sakura Finetek USA, 
Torrance, CA, USA) and stored at $-80{ }^{\circ} \mathrm{C}$. Before sectioning the membranes, each block was warmed to $-20^{\circ} \mathrm{C}$ and then maintained at this temperature throughout sectioning. Then, ERMs were cut into $6-\mu \mathrm{m}$ sections by Frigocut $2800 \mathrm{~N}$ Cryostat and mounted on slides. All sections were fixed by $4 \%$ paraformaldehyde (PFA) at room temperature for $30 \mathrm{~min}$ and stored at $-20^{\circ} \mathrm{C}$ before further processing [25].

\section{DNA constructs}

We used the CRISPR sgRNA designing tool to select a 20nt target sequence preceding a 5-NGG of a protospaceradjacent motif sequence on the P2 of MDM2 in the genomic locus (Rs2279744, NC_000012.12) [24]. The target sequence selected (5'- CGGGAGGTCCGGATGATCGC AGG-3') was located at P2 from 315 to 334 sites downstream of SNP309 and upstream of the Smad complex binding site (343-455) [22, 31]. A sequence of the lac Z gene from Escherichia coli was used as a control target (5'TGCGAATACGCCCACGCGATGGG-3'). dCas9 was generated from a lentiCRISPR v2 (Addgene: 52961, Cambridge, MA, USA) with two mutations (D10A mutagenic primer: 5'-CAGCATCGGCCTGGCCATCGGCACCAA CT-3' and H840A primer: 5'-CTGTCCGACTACGATGTG GACGCCATCGTGCCTCAGAG CTTTCTG-3') [27, 28]. dCas9-KRAB plasmid was purchased from Addgene (71236). Next, the annealed oligos were cloned into the modified vector dCas9 and dCas9-KRAB, and the clones were confirmed by Sanger DNA sequencing (Massachusetts General Hospital DNA core, Boston, MA, USA) using a primer (5'-GGACTATCATATGCTTACCG-3') of the U6 promoter.

\section{Cell culture}

ARPE-19 cells from the American Type Culture Collection (Manassas, VA, USA) were cultured in Dulbecco's modified Eagle's medium (DMEM; VWR, Radnor, PA, USA) with $10 \%$ bovine calf serum (BCS; Lonza, Walkersville, MD). All ARPE-19 cells used in our experiments were passage 5. Human embryonic kidney (HEK) $293 \mathrm{~T}$ cells (HEK 293, containing SV40 T-antigen) from the Dana-Farber Cancer Institute, Harvard Medical School (Boston, MA, USA) were cultured in DMEM with 10\% BCS. The medium to produce lentivirus by $293 \mathrm{~T}$ cells was DMEM supplemented with $30 \%$ fetal bovine serum (FBS; Lonza). All cells were cultured at $37^{\circ} \mathrm{C}$ in a humidified $5 \% \mathrm{CO}_{2}$ atmosphere.

\section{Production of the lentivirus}

The procedure for lentivirus production was described in detail in our previous publication [32]. In brief, the successfully cloned sgRNA-lentiCRISPR vector (2000 ng), the packaging plasmid psPAX2 (Addgene: 12260) (900 ng), and the envelope plasmid VSV-G (Addgene: 8454) $(100 \mathrm{ng}$ ) were mixed with $6 \mu \mathrm{l}$ lipofectamine 3000 (Thermo Fisher Scientific, Waltham, MA, USA) in $90 \mu$ OPTI-MEM (Thermo Fisher Scientific). Then the mixture was added to $293 \mathrm{~T}$ cells for producing lentivirus for 4 days. The harvested lentivirus was used to infect ARPE-19 cells supplemented with $8 \mu \mathrm{g} / \mathrm{mL}$ polybrene (Sigma-Aldrich Corp., St. Louis, MO, USA). Finally, the infected cells were selected in media containing $4 \mu \mathrm{g} / \mathrm{ml}$ puromycin (SigmaAldrich Corp.) for 4 weeks and subjected to western blot analysis for confirmation of the expression of MDM2 under TGF- $\beta 2$ stimulation.

\section{Chromatin immunoprecipitation (ChIP) assay for potential off-targets}

Potential off-targets of our designed $M D M 2$-sgRNA were found in the CRISPR designing tool (https://chopchop.cbu. uib.no/). Two off-targets were indicated, located at chr12: 57941706 (5'-CGGGAGCTCCGGACGAGCGCCGG-3') and chr20: 62323274 (5'-CGGGAGGACCGGATCATA GCGGG-3'). Primers for polymerase chain reaction (PCR) were designed as follows: chr12: 57941706 (OF1F:5'TTACCTTTCCCAGTCTCGCTCT-3', OF1R:5'-TGGTG AAGAAGCT GGAGAAGAA-3') and chr20: 62323274 (OF2F:5'-TTGTAGTAGGG AGAAAGGGT-3', OF2R:5'TAAGTAGGCTGTGTGCCTGAT-3'). The ChIP assay was conducted to detect the binding of dCas9 to target sites and/or potential off-targets according to a simplified protocol [33]. In brief, the cross-link of protein-DNA complexes was performed by adding $37 \%$ PFA diluted to a $1 \%$ final concentration and cells were incubated at room temperature for $15 \mathrm{~min}$. Glycine $(125 \mathrm{mM})$ was applied for quenching the fixation. Five hundred microliters lysis buffer $(10 \mu \mathrm{g} / \mathrm{mL}$ leupeptin, $10 \mu \mathrm{g} / \mathrm{mL}$ aprotinin, and $1 \mathrm{mM}$ phenylmethylsulfonyl fluoride (PMSF)) was added per $5 \times 10^{6}$ cells for resuspension. Cell lysates were sonicated to shear chromatin to an average length of $\sim 1 \mathrm{~kb}$. After being centrifuged at $12,000 \times g$, the supernatant was collected. Agarose beads were incubated with $5 \mu$ g anti-Cas 9 primary antibody at $4{ }^{\circ} \mathrm{C}$ on a rotating device for $2 \mathrm{~h}$ for a better combination. Then the prepared samples were added to the beads and incubated at $4{ }^{\circ} \mathrm{C}$ overnight. The following day, beads were collected after centrifugation and washed four times. One hundred microliters TrisEDTA buffer was added to the sample and boiled for $10 \mathrm{~min}$. Finally, samples were centrifuged for $1 \mathrm{~min}$ at $12,000 \times g$ and supernatant was collected into a clean tube. The ChIP sample was amplified by PCR with the above primers and subjected to gel analysis to detect the dCas9 binding site. 


\section{Western blot analysis}

After being serum-starved and treated by TGF- $\beta 2$, combined EGF and FGF-2, or TNF- $\alpha$. ARPE-19 cells were washed twice in ice-cold PBS; cell lysates were harvested in extraction buffer (10 mM Tris- $\mathrm{HCl}$ [pH 7.4], $5 \mathrm{mM}$ EDTA, $50 \mathrm{mM} \mathrm{NaCl}, 50 \mathrm{mM} \mathrm{NaF}, 1 \%$ Triton X-100, $20 \mu \mathrm{g} / \mathrm{ml}$ aprotinin, $2 \mathrm{mM} \mathrm{Na}_{3} \mathrm{VO}_{4}$, and $1 \mathrm{mM} \mathrm{PMSF}$ ), and $5 \times$ protein loading buffer ( $25 \mathrm{mM}$ EDTA [pH $=7.0], 10 \%$ SDS, 500 $\mathrm{mM}$ dithiothreitol, $50 \%$ sucrose, $500 \mathrm{mM}$ Tris- $\mathrm{HCl}[\mathrm{pH}=$ 6.8], and $0.5 \%$ bromophenol blue) was added for the final concentration as $1 \times$ in protein samples. Samples were boiled for $5 \mathrm{~min}$ and then centrifuged for $5 \mathrm{~min}$. Proteins were separated by SDS-PAGE, transferred to polyvinylidene difluoride membranes, and subjected to western blot analyses using the primary antibodies $(1: 10000$ for $\beta$ actin, 1:1000 for others). All experiments were repeated a minimum of three times. Signal intensity was determined by densitometry using ImageJ software (National Institutes of Health, Bethesda, MD, USA).

\section{Immunofluorescence (IF)}

Cells were seeded on 13-mm coverslips in 24-well plates. After being starved and treated with TGF- $\beta 2$, the cells on the coverslips were washed twice in PBS, fixed in 4\% PFA at room temperature for $30 \mathrm{~min}$ and then permeabilized in $0.3 \%$ Triton X-100 for 30 min. Blocking buffer with $5 \%$ normal goat serum in $0.3 \%$ Triton X-100 was applied to the cells for $30 \mathrm{~min}$ to reduce non-specific staining, and cells were incubated with primary antibodies $(1: 200)$ at $4{ }^{\circ} \mathrm{C}$ overnight. Primary antibodies were omitted in the negative controls. The following day, the cells were incubated with fluorescent secondary antibodies for $30 \mathrm{~min}$ at room temperature. Finally, all coverslips were taken out and mounted in mounting solution with DAPI on the slides. Cell morphology was photographed by EVOS FL Auto microscope (Thermo Fisher Scientific), and fluorescence from cells was imaged using a Fluorescent Microscope Axioscope 2MOT Plus (Zeiss, Oberkochen, Germany). For ERMs, all slides were removed from $-20{ }^{\circ} \mathrm{C}$ and dried at room temperature. The following procedures were in accordance with IF on cells.

\section{RNA extraction and quantitative PCR (q-PCR)}

After cells were treated with TGF- $\beta 2$, total RNA was extracted using an RNeasy Mini Kit (Qiagen, Hilden, Germany). Next, reverse transcription was conducted in an RNase-free environment using an iScript cDNA synthesis kit (Bio-rad Laboratories, Hercules, CA). Finally, $5 \mu \mathrm{l} 2 \times$ SYBR Green Master (Roche Diagnostics, Mannheim, Germany) was added in a $10 \mu \mathrm{l}$ reaction system containing
$0.5 \mu \mathrm{l}$ forward primer $(10 \mu \mathrm{M}), 0.5 \mu \mathrm{l}$ reverse primer $(10 \mu \mathrm{M}), 1 \mu \mathrm{l}$ cDNA, and $4 \mu \mathrm{l} \mathrm{H}_{2} \mathrm{O}$ on a LightCycler 480 instrument (Roche Diagnostics). The MDM2 primers used in this study were designed as follows: Forward: $5^{\prime}-\mathrm{G}$ TGCATTTCCAATAGTCAGCTAA-3', Reverse: 5'-AGA AGGACAAGAACTCTCAGATG-3'.

\section{Wound-healing assay}

A wound-healing assay was performed as previously described [32]. ARPE-19 cells were seeded in 24-well plates. After reaching confluence, they were starved for $24 \mathrm{~h}$ and then the cell monolayers were scraped with a $200 \mu \mathrm{l}$ sterile pipette tip. The cells were washed three times in PBS to remove detached cells and then treated with TGF- $\beta 2$ (10 $\mathrm{ng} / \mathrm{ml}$ ) in serum-free medium. The wound was photographed at 0 and $24 \mathrm{~h}$ with the EVOS FL Auto microscope after scraping. Quantification was conducted by measuring the number of pixels in the wound area using ImageJ software.

\section{Proliferation assay}

ARPE-19 cells were seeded into 24-well plates at a density of 30,000 per well in DMEM medium. After being starved for $24 \mathrm{~h}$, TGF- $\beta 2(10 \mathrm{ng} / \mathrm{ml})$ was added to the cells in a serum-free condition and the same concentration of TGF- $\beta 2$ treatment was repeated daily. After $48 \mathrm{~h}$, the cells were trypsinized and counted using a hemocytometer under a light microscope. Two counts were performed for each of the three replicates in one experiment, and a total of three independent experiments were performed.

\section{Results}

\section{MDM2 expression in ERMs from PVR patients}

ERMs were harvested from Grade C PVR patients and subjected to IF staining for MDM2 expression. Cytokeratin was applied as the biomarker of RPEs. As shown in Fig. 1, MDM2 (in red) was highly expressed in the ERMs, and costaining of MDM2 with Cytokeratin (in green) suggests that MDM2 was expressed in RPEs in the ERMs.

\section{TGF- $\beta 2$-induced MDM2 expression in ARPE-19 cells}

TGF- $\beta 2$ is elevated in the vitreous of PVR patients and experimental animals, playing a critical role in EMT $[34,35]$. Moreover, MDM2 was highly expressed in the ERMs from patients with PVR (Fig. 1); therefore, we examined if TGF- $\beta 2$ could induce the expression of MDM2 in human RPEs, namely, ARPE-19 cells. To answer this 
Fig. 1 MDM2 expression in ERMs from PVR patients. ERMs were harvested from Grade C PVR patients.

Immunofluorescent staining was conducted for expression of MDM2 (red) and Cytokeratin (green). No primary antibodies were applied to the negative controls. MDM2 mouse double minute 2, ERM epiretinal membrane, PVR proliferative vitreoretinopathy. Scale bar, $100 \mu \mathrm{m}$

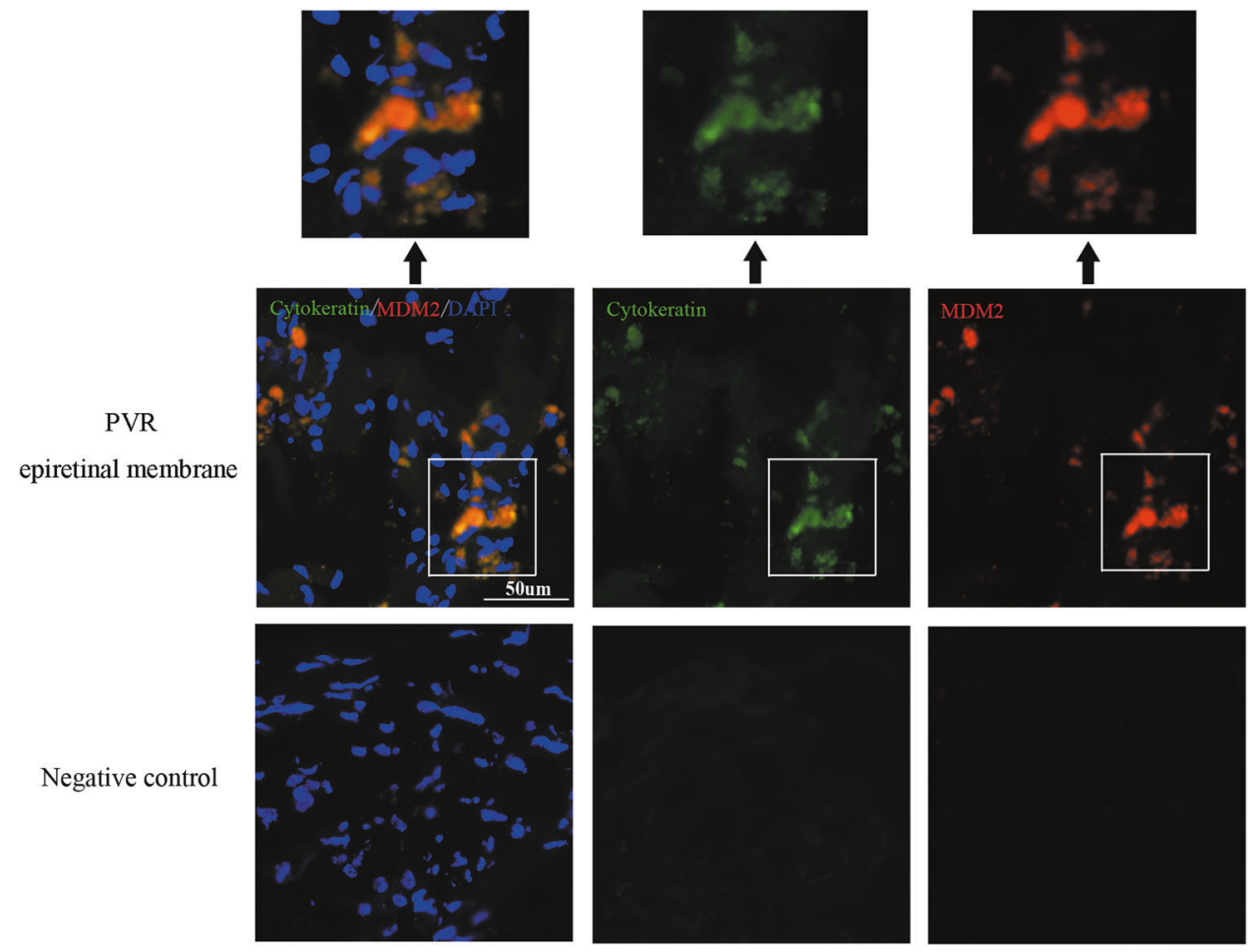

question, ARPE-19 cells were seeded in 24-well plates, starved in serum-free medium for $24 \mathrm{~h}$, and then treated with TGF- $\beta 2(10 \mathrm{ng} / \mathrm{ml})$ for 24,48 , and $72 \mathrm{~h}$, respectively. Our western blot results demonstrated that MDM2 expression had elevated significantly at $24 \mathrm{~h}(\mathrm{MD}=1.01,95 \% \mathrm{CI}$ : $0.57-1.45, P=0.0004)$ and $48 \mathrm{~h}(\mathrm{MD}=0.86,95 \% \mathrm{CI}$ : $0.41-1.30, P=0.0012$ ) (Fig. 2).

\section{TGF- $\beta 2$-induced EMT in ARPE-19 cells}

Our goal in this project was to explore the role of MDM2 in EMT in human RPEs as related to PVR pathogenesis; therefore, we first established the best condition to induce EMT. Cells were seeded in plates for western blot analysis and on coverslips for IF. To induce EMT, TGF- $\beta 2$ (10 ng/ $\mathrm{ml}$ ) was added for 24,48 , and $72 \mathrm{~h}$, respectively, after cells were starved for $24 \mathrm{~h}$. Fibronectin, N-cadherin, and Vimentin were used as EMT biomarkers. As a result, western blot analysis showed the expression of Fibronectin (MD $=0.45,95 \% \mathrm{CI}: 0.02-0.87, P=0.036), \mathrm{N}-$ cadherin $(\mathrm{MD}=0.53,95 \% \mathrm{CI}: 0.11-0.96, P=0.010)$, and Vimentin $(\mathrm{MD}=0.44,95 \% \mathrm{CI}: 0.01-0.86, P=$ 0.041 ) had increased significantly after $48 \mathrm{~h}$ (Fig. 3a). The morphology of ARPE-19 cells changed from hexagonal to spindle-shaped, and the staining of all three biomarkers were enhanced with the stimulation of TGF- $\beta 2$ (Fig. 3b), which were in accord with the changes observed by western blotting.

\section{dCas9/MDM2-sgRNA blocked TGF- $\beta 2$-induced MDM2 expression}

To express dCas9, we induced two mutations (D10A and H840A) in a purchased lenti-CRISPR/Cas9 vector (Fig. 4a). A 20-nt target sequence targeting P2 was cloned into the mutant lenti-CRISPR/dCas9 vector [31] (Fig. 4a, b). The successful cloning was determined using Sanger sequencing (Fig. 4b). This mutant lentiviral vector with an MDM2sgRNA was transfected into $293 \mathrm{~T}$ cells to produce the lentivirus, which was used to infect the ARPE-19 cells for selection by puromycin.

To test the efficacy of MDM2 suppression, cells were treated with TGF- $\beta 2(10 \mathrm{ng} / \mathrm{ml})$ for $24 \mathrm{~h}$. Cell lysates were subjected to western blot analysis and q-PCR. Our results showed that TGF- $\beta 2$-induced MDM2 expression and dCas9 directed by $M D M 2$-sgRNA targeting P2 significantly blocked TGF- $\beta 2$-stimulated expression of MDM2 (Fig. 4c, western blot: $\mathrm{MD}=0.46,95 \%$ CI: $0.37-0.55, P=0.0008$; Fig. 4d, q-PCR: $\mathrm{MD}=2.09,95 \% \mathrm{CI}: 1.52-2.67, P<$ 0.0001).

Potential off-targets were determined by a ChIP assay. DNA fragments from the ChIP assay using an antibody against Cas9 were subjected to PCR with three pairs of primers, whose products were expected to cover both the target site and the two most potential off-targets. As shown in Fig. 4e, two potential off-targets were shown with three mismatches in each. The PCR results revealed 
Fig. 2 TGF- $\beta 2$ promotes MDM2 expression in ARPE-19 cells. Western blot analysis of MDM2 expression under TGF- $\beta 2$ $(10 \mathrm{ng} / \mathrm{ml})$ stimulation for 24 , 48 , and $72 \mathrm{~h}$. MDM2 mouse double minute 2 , TGF- $\beta 2$ transforming growth factor-beta 2. $* * P<0.01 ; * * * P<0.001$
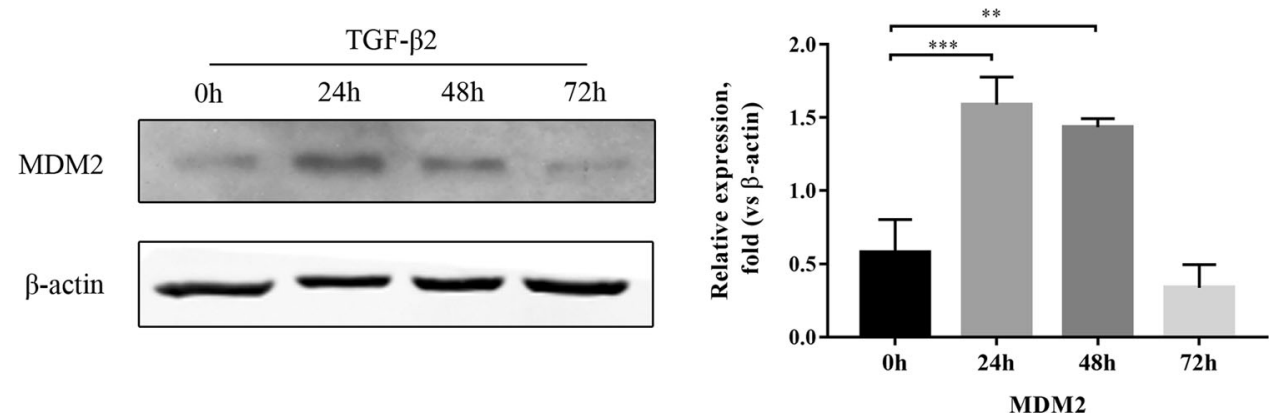

A
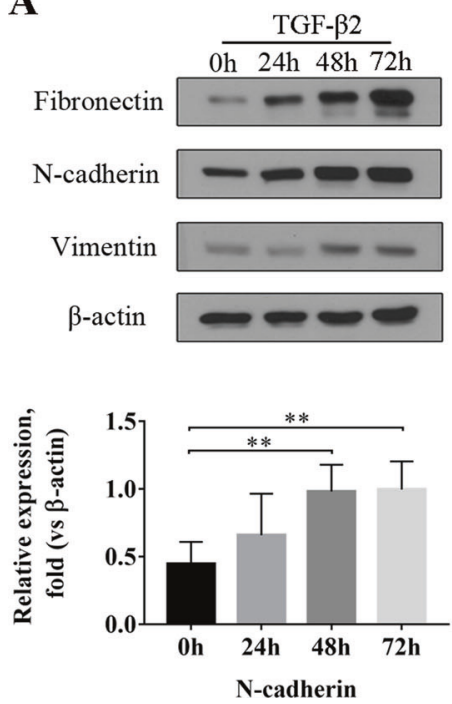

Fig. 3 TGF- $\beta 2$ induces EMT in ARPE- 19 cells. a Western blot analysis of EMT biomarkers Fibronectin, N-cadherin and Vimentin in ARPE-19 cells after TGF- $\beta 2(10 \mathrm{ng} / \mathrm{ml})$ stimulation for 24,48 , and $72 \mathrm{~h}$; b IF for the above EMT biomarkers in ARPE-19 cells treated
B
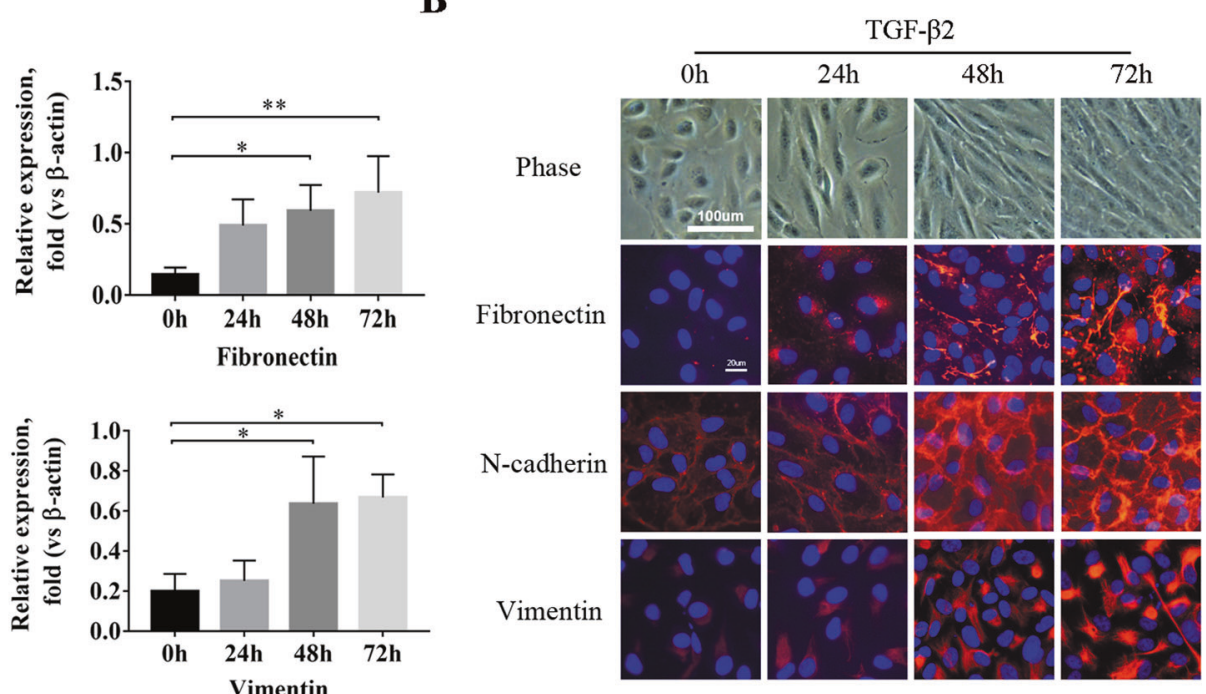

with TGF- $\beta 2$ at the specific time points. Scale bar, $100 \mu \mathrm{m}$ (phase), $20 \mu \mathrm{m}$ (Fluorescence); EMT epithelial to mesenchymal transition, TGF- $\beta 2$ transforming growth factor-beta 2 , IF immunofluorescence. $* P<0.05 ; * * P<0.01$ a PCR product from the primers for the target site ( 400-bp as expected); however, no PCR products appeared from the primers covering the potential two offtargets, suggesting that there were no off-target effects for this dCas9/MDM2-sgRNA. In addition, three PCR products were revealed by using total genomic DNA isolated from ARPE-19 cells using three pairs of primers, demonstrating that no systemic problem existed in the PCR procedure.

\section{dCas9-KRAB/MDM2-sgRNA attenuated basal expression of MDM2}

To compare the efficacy of dCas9 with dCas9-KRAB, the same target sequence at $\mathrm{P} 2$ was cloned into the pLV-sgRNAdCas9-KRAB vector and the cloning was determined by Sanger DNA sequencing (Fig. 5a). The confirmed lentiviral vector was used to transfect $293 \mathrm{~T}$ cells for producing the lentivirus, that was used to infect the ARPE-19 cells. Next, western blot analysis and wound-healing assays were performed to evaluate the effect of dCas9-KRAB/MDM2sgRNA-mediated MDM2 suppression. Compared with dCas9/MDM2-sgRNA, dCas9-KRAB/MDM2-sgRNA not only blocked TGF- $\beta 2$-induced expression of MDM2, but also suppressed the basal expression of MDM2 in the unstimulated condition (Fig. $5 \mathrm{~b}$, TGF- $\beta 2$ treated: $\mathrm{MD}=2.53,95 \% \mathrm{CI}$ : $1.18-3.88, P=0.0014$; TGF- $\beta 2$ untreated: $\mathrm{MD}=1.40,95 \%$ CI: $0.05-2.74, P=0.04)$. Similarly, the cells with dCas9$\mathrm{KRAB} / M D M 2$-sgRNA showed less migration ability, whether they were TGF- $\beta 2$ treated $(\mathrm{MD}=40.90,95 \% \mathrm{CI}$ : $31.20-50.59, P<0.0001)$ or untreated (MD $=24.37,95 \%$ CI: 14.67-34.06, $P=0.0003$ ), than did cells with lacZ controls (Fig. 5c, d). Because dCas9-KRAB/MDM2-sgRNA suppressed basal MDM2 expression, their transduced cells could not survive for a long time. Finally, we chose dCas9/MDM2sgRNA for the following experiments. 
A $\quad 52961$ (Addgene)

\begin{tabular}{|l|l|l|l|}
\hline LTR & $\mathrm{U} 6 \mathrm{SgNA}$ & $\mathrm{EF}-1 \alpha$ \\
\hline
\end{tabular}

\begin{tabular}{|c|c|}
\hline SpCas9 & LTR \\
\hline
\end{tabular}

\begin{tabular}{|l|l|l|l|l|l|}
\hline LTR & U6 & SgRNA & EF-1 & Sp-dCas9 (D10A \& H840) & LTR \\
\hline
\end{tabular}

B Promoter 1 basal expression

Promoter 2

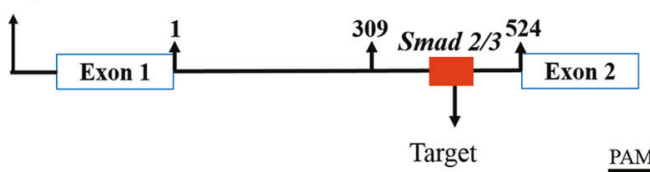

5'-CGGGAGGTCCGGATGATCGCAGG- 3'

3'-GCCC TCCAGGCCTACTAGCGTCC- 5'

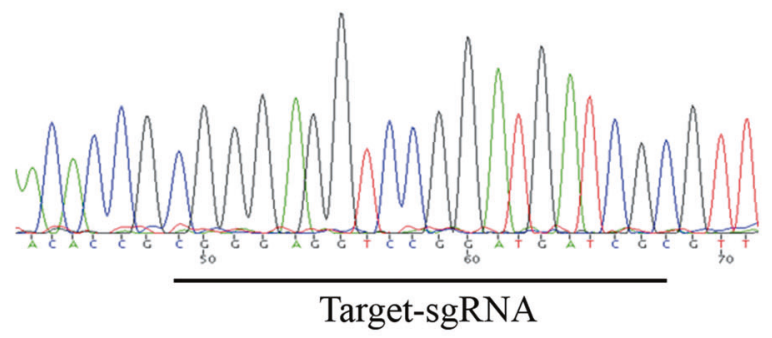

C

D

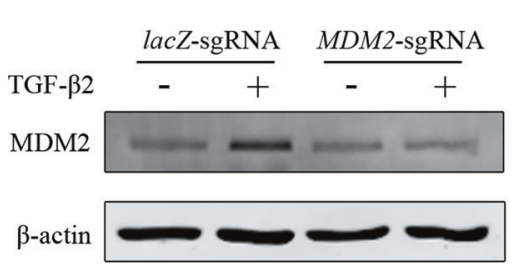

$\mathbf{E}$
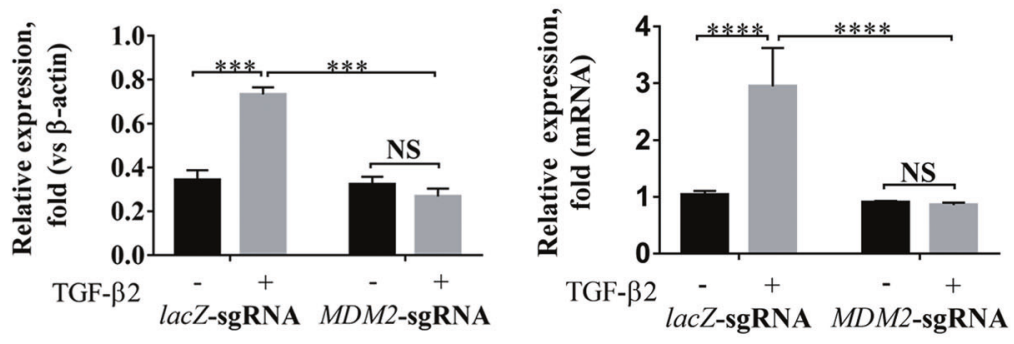

MDM2-Target site CGGGAGGTCCGGATGATCGCAGG Off-target 1 (OF1) chr12:57941706 CGGGAGCTCCGGACGAGCGCCGG Off-target 2 (OF2) chr20:62323274 CGGGAGGACCGGATCATAGCGGG

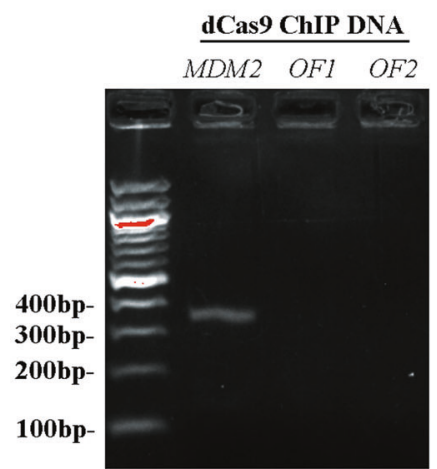

Fig. 4 dCas9/MDM2-sgRNA blocks TGF- $\beta 2$-induced MDM2 expression. a Schematic diagram of the construction of lenti-CRISPR/dCas9 vector; b Sanger sequencing of the successful cloning of MDM2 target into the dCas9 vector; $\mathbf{c}$ Western blot analysis of MDM2 expression in lacZ-sgRNA- and MDM2-sgRNA- transduced ARPE-19 cells under TGF- $\beta 2(10 \mathrm{ng} / \mathrm{ml})$ stimulation for $24 \mathrm{~h}$; d q-PCR analysis of $M D M 2$ expression in lacZ-sgRNA- and $M D M 2$-sgRNA-transduced ARPE-19 cells under TGF- $\beta 2(10 \mathrm{ng} / \mathrm{ml})$ stimulation for $24 \mathrm{~h}$. e dCas 9 binding to

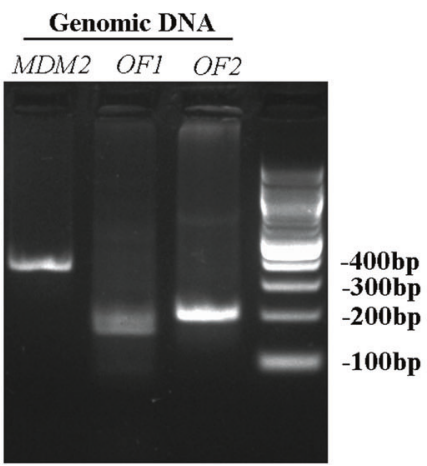

target sites and/or off-targets were determined by ChIP assay. DNA samples from ChIP were subjected to PCR and gel analysis. Genomic DNA from wild-type ARPE-19 cells served as controls. TGF- $\beta 2$ transforming growth factor-beta 2, MDM2 mouse double minute 2, CRISPR clustered, regularly interspaced, short palindromic repeats, dCas9 inactive CRISPR-associated endonuclease 9, sgRNA smallguide RNA, ChIP chromatin immunoprecipitation. $* * * P<0.001$; $* * * * P<0.0001$ 
Fig. 5 dCas9-KRAB/MDM2sgRNA attenuates basal expression of MDM2. a Schematic diagram of dCas9KRAB structure and Sanger sequencing of the target sequences cloned into the vector; b Western blot analysis of MDM2 expression in lacZsgRNA- and $M D M 2$-sgRNA (KRAB)-transduced ARPE-19 cells under TGF- $\beta 2(10 \mathrm{ng} / \mathrm{ml})$ stimulation for $24 \mathrm{~h}$; c Quantitative results of the wound-healing assay (images in d) in lacZ-sgRNA- and MDM2sgRNA (KRAB)-transduced ARPE-19 cells after TGF- $\beta 2$ $(10 \mathrm{ng} / \mathrm{ml})$ stimulation for $24 \mathrm{~h}$. d Representative images of the wound-healing assay described in Fig. 3. Scale bar, $400 \mu \mathrm{m}$. TGF- $\beta 2$ transforming growth factor-beta 2, KRAB Kruppel associated box, dCas9 inactive CRISPR-associated endonuclease 9, sgRNA smallguide RNA. $* * * P<0.001$; $* * * * P<0.0001$

A

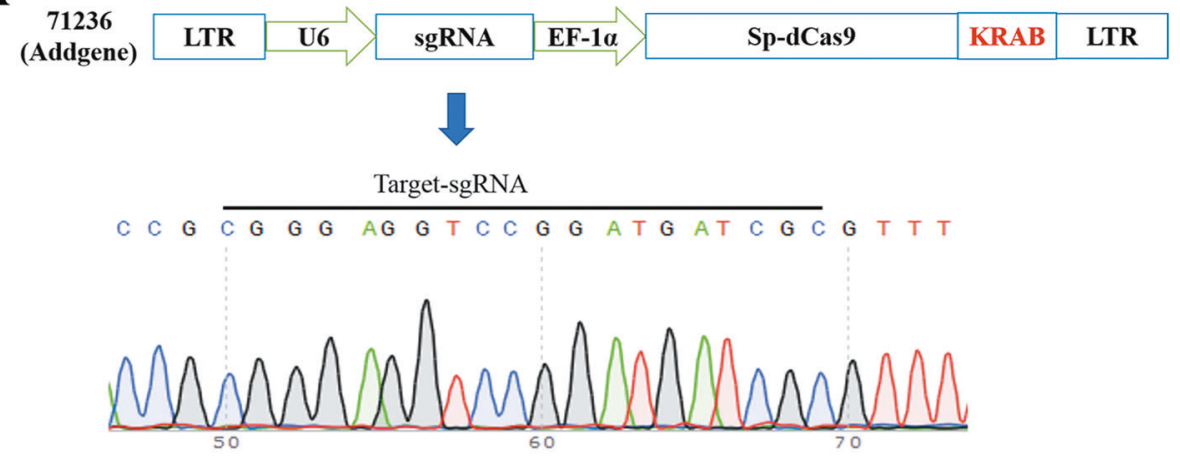

B

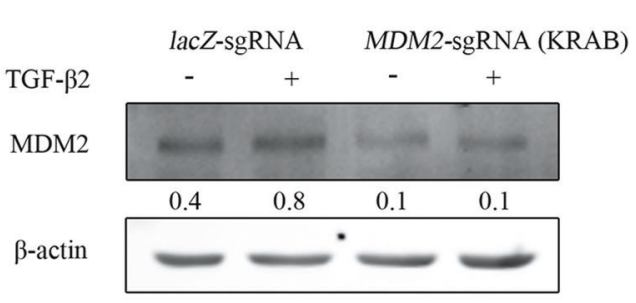

D

$\mathrm{Oh}$

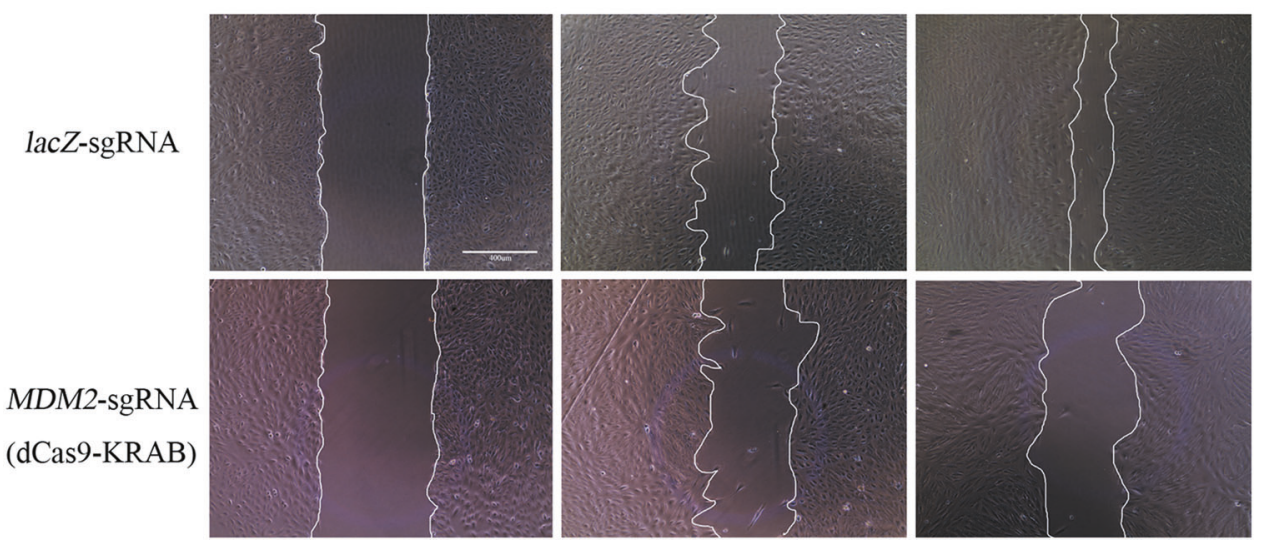

C

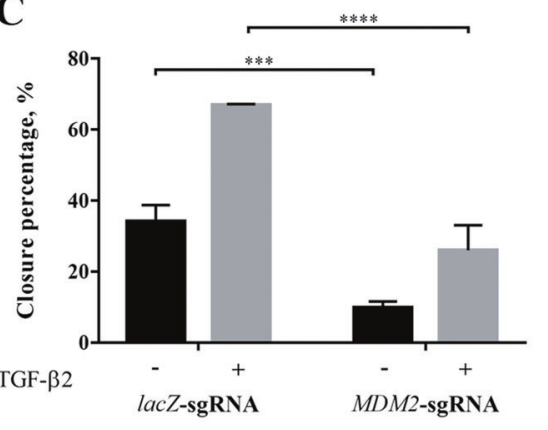

TGF- $\beta 2$

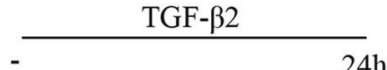

\section{dCas9/MDM2-sgRNA blocked EMT induced by TGF- $\beta 2$ and MDM2 expression induced by EGF, FGF-2, and TNF-a}

TGF- $\beta 2$-induced expression of MDM2 was successfully suppressed by the dCas9/MDM2-sgRNA in ARPE-19 cells. To investigate the role of MDM2 in EMT, we examined the expression of TGF- $\beta 2$-induced EMT biomarkers (Fibronectin, $\mathrm{N}$-cadherin and Vimentin) in dCas9/MDM2-sgRNAtransduced cells, which were treated with TGF- $\beta 2$ (10 ng/ $\mathrm{ml}$ ) for $48 \mathrm{~h}$. LacZ-sgRNA-transduced ARPE-19 cells were used as a control. Western blot analysis showed that the TGF- $\beta 2$-stimulated expression of Fibronectin, N-cadherin, and Vimentin in $M D M 2$-sgRNA-transduced cells was significantly less than those in controls (Fig. 6a, Fibronectin: $\mathrm{MD}=1.13,95 \% \mathrm{CI}: 0.77-1.49, P=0.0053 ; \mathrm{N}-$ cadherin: $\mathrm{MD}=0.58,95 \%$ CI: $0.35-0.81, P=0.0002$; Vimentin: $\mathrm{MD}=0.49,95 \%$ CI: $0.23-0.75, P=0.0082)$. In addition, under TGF- $\beta 2$ stimulation there were fewer changes observed in the morphology of MDM2-sgRNAtransduced ARPE-19 cells than in controls, and less of an increase in expression of EMT biomarkers than in cells with lacZ-sgRNA control (Fig. 6b).

Furthermore, we expanded our above findings to examine if other growth factors could induce MDM2 expression and if dCas9/MDM2-sgRNA could block this change. We selected combined EGF and FGF or TGF- $\alpha$ to stimulate cells, because these growth factors or cytokines 
A

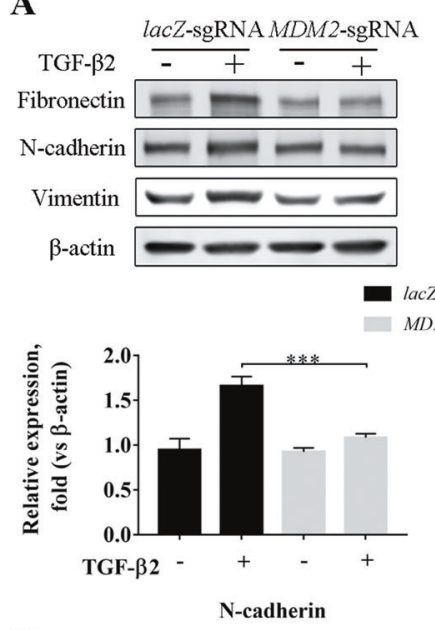

C

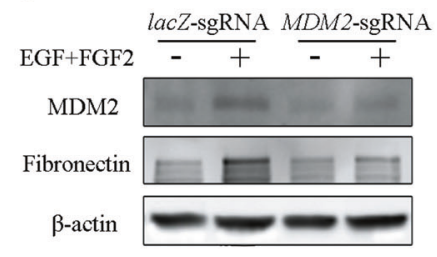

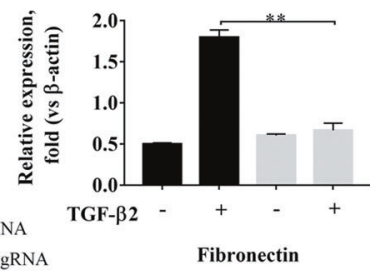

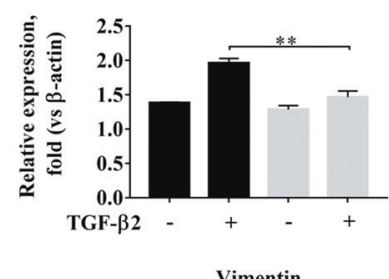

Vimentin

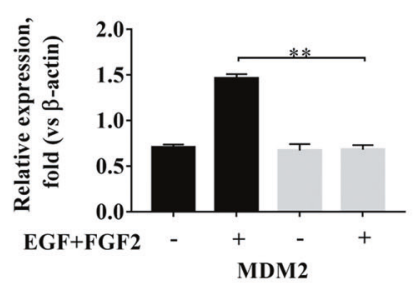

B

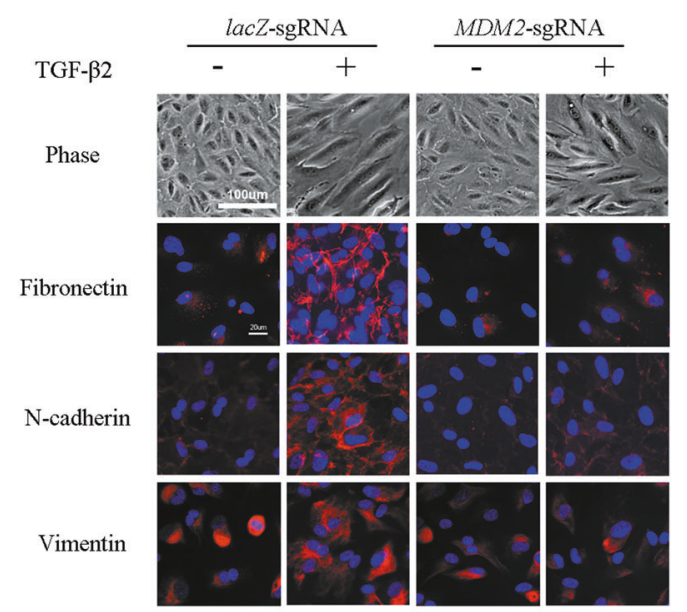

D
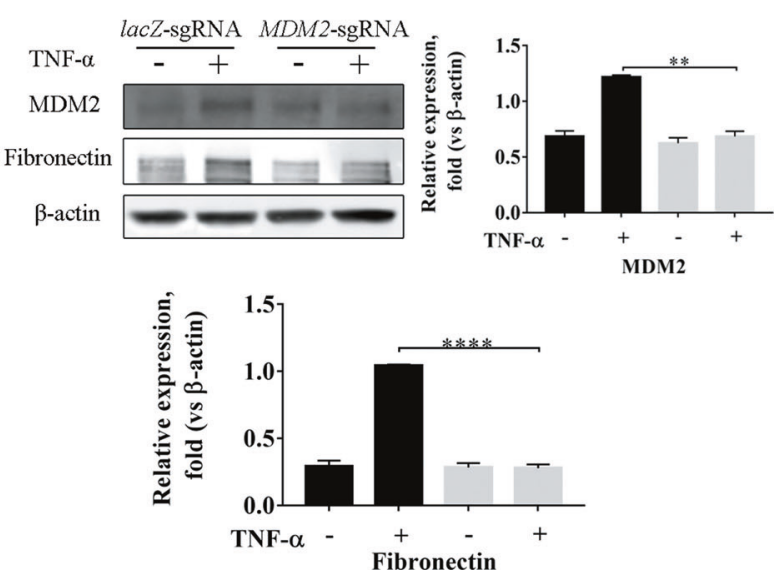

d Western blot analysis of MDM2 and EMT marker Fibronectin in lacZ-sgRNA- and MDM2-sgRNA-transduced ARPE-19 cells after

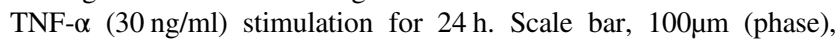

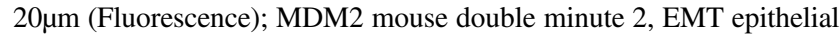
to mesenchymal transition, TGF- $\beta 2$ transforming growth factor-beta 2, EGF epidermal growth factor, FGF-2 fibroblast growth factor, TNF- $\alpha$ tumor necrosis factor-alpha, IF immunofluorescence, sgRNA smallguide RNA, NS no significance. $* * P<0.01$; $* * * P<0.001$; **** $P<$ 0.0001

95\% CI: $0.69-0.84, P<0.0001)$. These outcomes demonstrated that dCas9/MDM2-sgRNA could also block combined EGF and FGF-2- or TNF- $\alpha$-induced expression of MDM2 in ARPE-19 cells.

\section{Blocking the MDM2-p53 interaction by Nutlin-3 inhibited TGF- $\beta 2$-induced EMT}

Nutlin-3 is a small-molecule MDM2 inhibitor blocking the interaction of MDM2 and p53. To explore if the modulation of EMT by MDM2 is p53-dependent, we applied $10 \mu \mathrm{M}$ Nutlin-3 to ARPE-19 cells; this concentration was based on previous publications [38, 39]. After serum-starvation, cells were pretreated with Nutlin-3 for $30 \mathrm{~min}$, and then treated with TGF- $\beta 2$ for additional $48 \mathrm{~h}$. Western blot analysis 
A
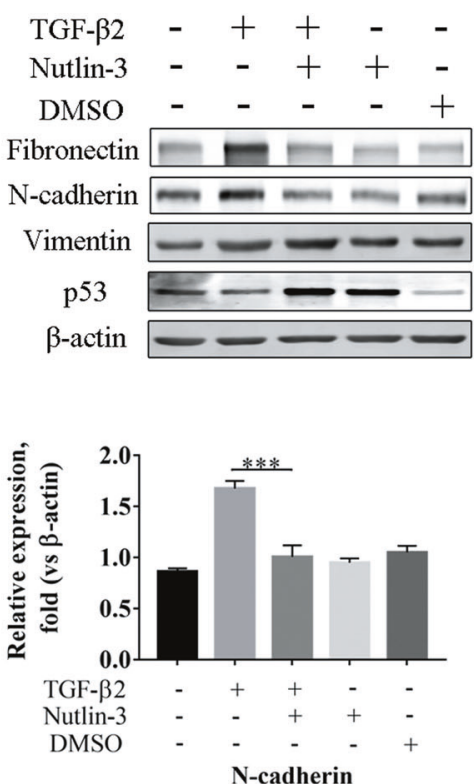

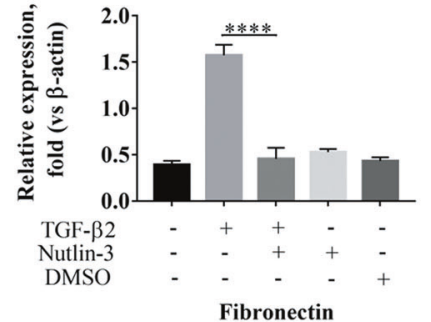

Fibronectin
B

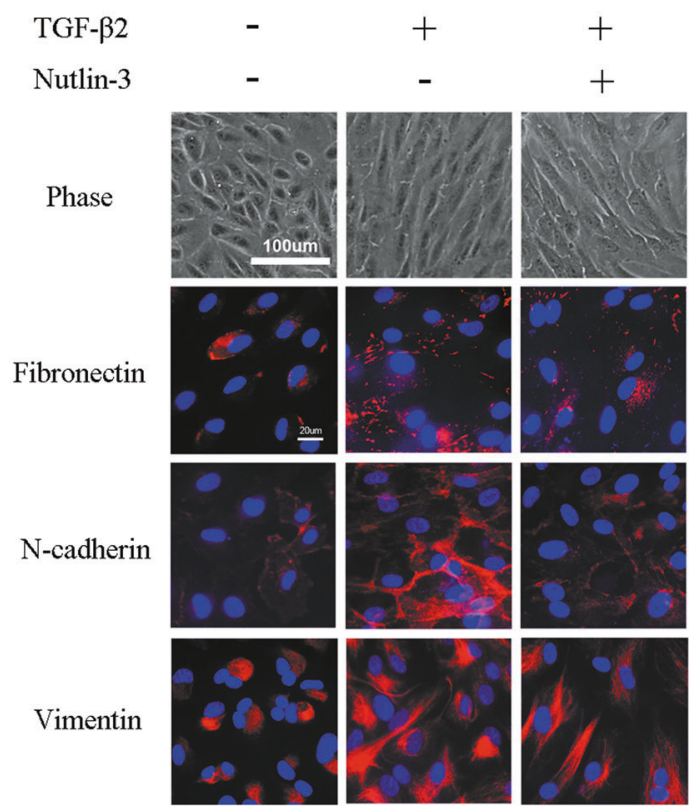

Fig. 7 Blocking the MDM2-p53 interaction by Nutlin-3 inhibits TGF$\beta 2$-induced EMT. a Western blot analysis of EMT biomarkers Fibronectin, N-cadherin and Vimentin in ARPE-19 cells after TGF- $\beta 2$ (10 ng/ $\mathrm{ml})$ stimulation for $48 \mathrm{~h}$ with or without Nutlin-3 $(10 \mu \mathrm{M})$; b IF for the above EMT biomarkers in ARPE-19 cells at the specific time points. Scale bar, $100 \mu \mathrm{m}$ (phase), $20 \mu \mathrm{m}$ (Fluorescence); EMT epithelial to mesenchymal transition, TGF- $\beta 2$ transforming growth factor-beta 2 , IF immunofluorescence, NS no significance. $* * * P<0.001$; $* * * * P<0.0001$ showed that Nutin-3 suppressed a TGF- $\beta 2$-induced increase in Fibronectin and N-cadherin; however, Nutlin-3 had little impact on TGF- $\beta$-induced expression of Vimentin (Fig. 7a, Fibronectin: $\mathrm{MD}=1.18$, 95\% CI: $0.90-1.33, P<0.0001$; N-cadherin: $\mathrm{MD}=0.67$, 95\% CI: $0.45-0.89, P=0.0004$; Vimentin: $\mathrm{MD}=0.05$, 95\% CI: $-0.23-0.36, P=0.98)$. Results of IF showed similar tendencies (Fig. 7b).

\section{dCas9/MDM2-sgRNA prevented TGF- $\beta 2$-induced motility of ARPE-19 cells}

In PVR, RPEs gain a better ability to migrate and proliferate under the stimulation of growth factors. To examine cells' motility, migration and proliferation assays were performed on dCas9/MDM2-sgRNA-transduced ARPE-19 cells. Cells with dCas9/lacZ-sgRNA were used as controls. Migration was measured by a wound-healing assay and proliferation was determined by cell counting using a hemocytometer. Consequently, we found that dCas9/MDM2-sgRNA attenuated TGF- $\beta 2$-induced cell migration (Fig. $8 \mathrm{a}, \mathrm{b}, \mathrm{MD}=$ 20.03, 95\% CI: 17.00-23.05, $P<0.0001)$ and proliferation (Fig. $8 \mathrm{c}, \mathrm{MD}=1.73$, 95\% CI: 0.65-2.81, $P=0.005$ ).

\section{Discussion}

In this study, dCas9/MDM2-sgRNA was employed to block P2-driven MDM2 expression and TGF- $\beta 2$-induced MDM2- dependent EMT in ARPE-19 cells. The protospacer of this sgRNA was located downstream of the MDM2 SNP309, that is, independently of this SNP. Consequently, TGF- $\beta 2$ induced expression of MDM2 and EMT biomarkers was indeed blocked by dCas9/MDM2-sgRNA. In addition, TGF- $\beta 2$-induced motility of cells was also attenuated by dCas9/MDM2-sgRNA. In the original CRISPR/Cas9 system, an sgRNA was introduced to target genomic DNA for a specific double-strand DNA break [40]. We generated two mutations (D10A and H840A) in Cas9 to yield a dCas9, which lost its nuclease activity but kept its ability to bind a specific sequence guided by sgRNA instead of breaking it [28, 29, 41]. dCas9 has been confirmed to silence the target gene. Our MDM2-sgRNA targets P2, thus the basal expression of MDM2 was retained without interference, to maintain the cells' viability.

MDM2, as an oncogene protein, has been widely researched in cancers. Overexpression of MDM2 is found in $\sim 7 \%$ of human cancers containing more than 4000 samples [42, 43]. The pathogenesis of high MDM2 level resulting in cancers includes SNP, enhanced transcription, and increased translation [23, 44]. P1 of MDM2 regulates the basal level expression, while the P2 located in the first intron is responsible for the inducible MDM2 expression [45]. Bougeard et al. first discovered MDM2 SNP309 to be related to tumor onset [46]. In Pastor-Idoate et al.'s study, 555 European PVR cases were included for genotyping the MDM2 SNP309 polymorphism. They finally found that the 
Fig. 8 Motility of ARPE-cells decreases after the expression of MDM2 is attenuated a Representative images of wound-healing assay in lacZsgRNA and MDM2-sgRNAtransduced ARPE-19 cells after TGF- $\beta 2(10 \mathrm{ng} / \mathrm{ml})$ stimulation for $24 \mathrm{~h}$. b Quantitative results of a wound-healing assay described in a. c Proliferation assay of lacZ-sgRNA- and MDM2-sgRNA-transduced ARPE- 19 cells after TGF- $\beta 2$ $(10 \mathrm{ng} / \mathrm{ml})$ stimulation for $24 \mathrm{~h}$. Scale bar, $400 \mu \mathrm{m}$; MDM2 mouse double minute 2 , TGF- $\beta 2$ transforming growth factor-beta 2, sgRNA small-guide RNA. $* * P<0.01 ; * * * * P<0.0001$

A

Oh
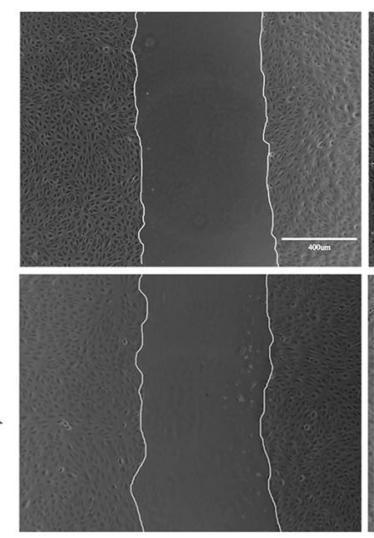

B

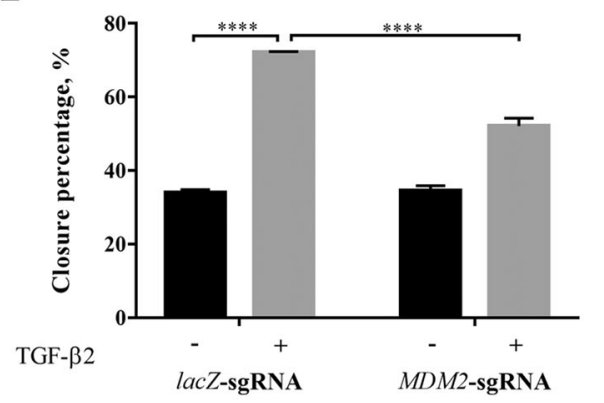

TGF- $\beta 2$
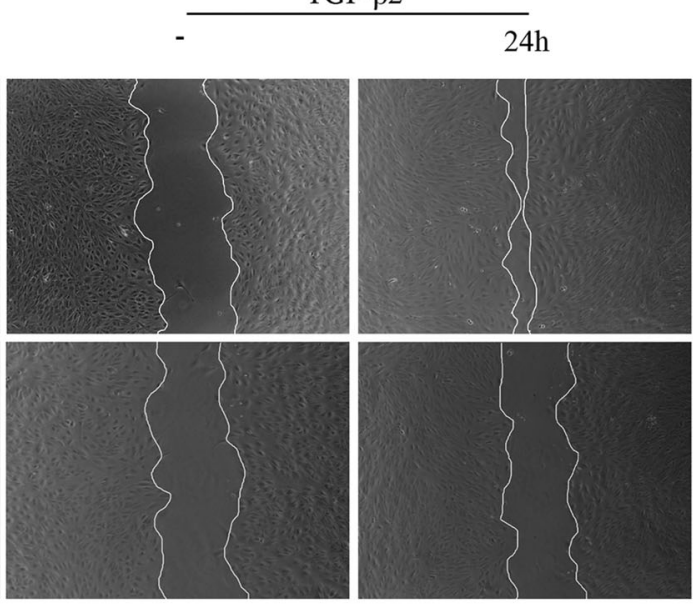

C

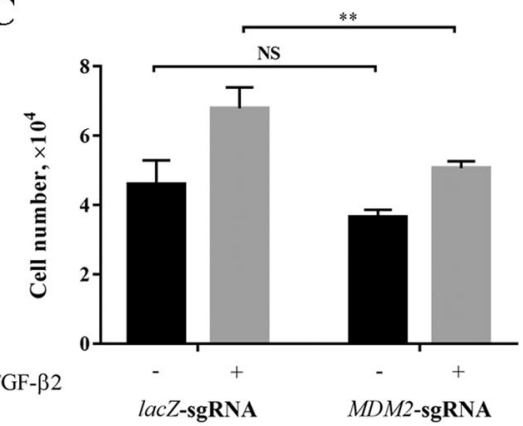

$G$ allele was associated with a higher risk of PVR among patients having a previous history of RD [5]. Subsequently, in former studies published by our group, we created the T309G mutation in primary fetal RPEs by CRISPR/Cas9, reaching the conclusion that the $G$ allele increased vitreousinduced expression of MDM2 and promoted proliferation of cells [24, 25].

However, $23.8 \%$ patients in the PVR group did not have the $\mathrm{G}$ allele of MDM2 SNP309 [5]. Therefore, in this project our goal was to block P2-driven MDM2 expression independently of SNP309. Moreover, ARPE-19 cells carry a heterozygous genotype $M D M 2^{S N P 309 T / G}$ with $55.3 \%$ having the $309 \mathrm{G}$ allele analyzed by next generation sequencing. To block P2-driven MDM2 expression, we selected MDM2sgRNA, which targets P2 from 315 to 335 downstream of the SNP309. P2 contains a variety of transcriptional factor binding sites including Smad 3/4 [31]. dCas9-KRAB was considered to have a higher efficiency for suppressing gene expression [30], and similar results to those we found in our above-described experiment (Fig. 5). However, we discovered that the basal expression of MDM2 was suppressed by dCas9-KRAB/MDM2-sgRNA even without TGF- $\beta 2$ stimulation. We assumed that dCas9-KRAB had a stronger affinity with the target site than dCas9 did, leading to a reduction basal MDM2 expression, thus cells could undergo apoptosis several days after expressing the dCas9-KRAB/
MDM2-sgRNA. Therefore, we chose dCas9/MDM2-sgRNAtransduced cells in the rest of our experiments, without interference to the cells' normal survival and motility.

Our results not only demonstrated TGF- $\beta 2$-induced MDM2 expression blocked by dCas9/MDM2-sgRNA, but also indicated that this blockade was accomplished when cells were stimulated by combined EGF and FGF-2, or TNF- $\alpha$ alone. These cytokines have been found to be elevated in PVR patients and animals, and to participate in the pathogenesis of PVR [35-37]. Moreover, they were used to induce EMT and migration in RPE cells in vitro according to published literature $[47,48]$. In addition, in our previous work, the combined growth factors-induced MDM2 expression in RPE cells via indirect activation of the PDGFreceptor alpha [37]. We expanded the efficacy of dCas9 to involve several kinds of growth factors or cytokinesinduced MDM2 increase, further enhancing our conclusions and promoting the potential application of dCas 9 vectors.

Nutlin-3 is a small-molecule inhibitor that blocks the interaction between MDM2 and p53, thus it has been considered in anti-cancer medications [49]. However, it resulted in serious adverse events [50]. Our aim was to block P2-driven expression of MDM2, whose function is dependent or independent of p53. We pretreated ARPE-19 cells with Nutlin-3 when TGF- $\beta 2$ was added and found that 
expression of two EMT biomarkers (Fibronectin and $\mathrm{N}$-cadherin) decreased. Therefore, MDM2 can function as a proinflammatory and oncogenic protein via p53-independent pathways, including $\mathrm{pRb}$ [20] and NF- $\mathrm{B}$ [51]. TGF- $\beta 2-$ induced expression of Vimentin was not blocked by Nutlin3 but was prevented by the dCas9/MDM2-sgRNA, probably through the p53-indepentent pathway.

Based on our results, MDM2 expression induced by a variety of growth factors and cytokines related to PVR can be suppressed by dCas9/MDM2-sgRNA. TGF- $\beta 2$ - stimulated expression of MDM2 and EMT biomarkers was blocked by the dCas9/MDM2-sgRNA in human RPEs. Therefore, CRISPR/dCas9 is a promising novel therapy for PVR that does not interfere with cellular basal gene expression and function. Further studies with primary RPEs on the mechanisms by which MDM2 modulates EMT are warranted to provide more evidence for our hypothesis.

Acknowledgements This work was supported by NIH R01EY012509 (HL), Research to Prevent blindness (HL), NIH National Eye Institute core grant P30EYE003790, and China Postdoctoral Science Foundation 2017M622912 (BL).

\section{Compliance with ethical standards}

Conflict of interest The authors declare that they have no conflict of interest.

Publisher's note: Springer Nature remains neutral with regard to jurisdictional claims in published maps and institutional affiliations.

\section{References}

1. Ryan SJ. The pathophysiology of proliferative vitreoretinopathy in its management. Am J Ophthalmol. 1985;100:188-93.

2. Pastor JC, de la Rúa ER, Martín F. Proliferative vitreoretinopathy: risk factors and pathobiology. Prog Retin Eye Res. 2002;21:127-44.

3. Pastor JC. Proliferative vitreoretinopathy: an overview. Surv Ophthalmol. 1998;43:3-18.

4. Abrams GW, Azen SP, McCuen BW 2nd, Flynn HW Jr, Lai MY, Ryan SJ. Vitrectomy with silicone oil or long-acting gas in eyes with severe proliferative vitreoretinopathy: results of additional and long-term follow-up. Silicone Study Report 11. Arch Ophthalmol. 1997; 115:335-44.

5. Pastor-Idoate S, Rodriguez-Hernandez I, Rojas J, Fernández I, García-Gutiérrez MT, Ruiz-Moreno JM, et al. Genetics on PVRSG: the T309G MDM2 gene polymorphism is a novel risk factor for proliferative vitreoretinopathy. PLoS ONE. 2013;8: e82283.

6. Casaroli-Marano RP, Pagan R, Vilaro S. Epithelial-mesenchymal transition in proliferative vitreoretinopathy: intermediate filament protein expression in retinal pigment epithelial cells. Invest Ophthalmol Vis Sci. 1999;40:2062-72.

7. Charteris DG, Sethi CS, Lewis GP. Proliferative vitreoretinopathy-developments in adjunctive treatment and retinal pathology. Eye. 2002;16:369-74.

8. Heimann H, Bartz-Schmidt KU, Bornfeld N. Scleral buckling versus primary vitrectomy in rhegmatogenous retinal detachment: a prospective randomized multicenter clinical study. Ophthalmology. 2007;114:2142-54.

9. Leiderman YI, Miller JW. Proliferative vitreoretinopathy: pathobiology and therapeutic targets. Semin Ophthalmol. 2009;24:62-9.

10. Tamiya S, Kaplan HJ. Role of epithelial-mesenchymal transition in proliferative vitreoretinopathy. Exp Eye Res. 2016;142:26-31.

11. Chiba C. The retinal pigment epithelium: an important player of retinal disorders and regeneration. Exp Eye Res. 2014;123: 107-14.

12. Chan CM, Chang HH, Wang VC, Huang CL, Hung CF. Inhibitory effects of resveratrol on PDGF-BB-induced retinal pigment epithelial cell migration via PDGFR $\beta$, PI3K/Akt and MAPK pathways. PLoS ONE. 2013;8:e56819.

13. Zeng K, Chen X, Hu X, Liu X, Xu T, Sun H, et al. LACTB, a novel epigenetic silenced tumor suppressor, inhibits colorectal cancer progression by attenuating MDM2-mediated p53 ubiquitination and degradation. Oncogene. 2018;37:5534-51.

14. Guo SJ, Zeng HX, Huang P, Wang S, Xie CH, Li SJ. MiR-508-3p inhibits cell invasion and epithelial-mesenchymal transition by targeting ZEB1 in triple-negative breast cancer. Eur Rev Med Pharmacol Sci. 2018;22:6379-85.

15. Jing W, Dong H, Min M, Runpeng Z, Xuewei X, Ru C, et al. Dependence of artesunate on long noncoding RNA-RP11 to inhibit epithelial-mesenchymal transition of hepatocellular carcinoma. J Cell Biochem. 2019;120:6026-34.

16. Oliner JD, Kinzler KW, Meltzer PS, George DL, Vogelstein B. Amplification of a gene encoding a p53-associated protein in human sarcomas. Nature. 1992;358:80-3.

17. Vassilev LT, Vu BT, Graves B, Carvajal D, Podlaski F, Filipovic $\mathrm{Z}$, et al. In vivo activation of the p53 pathway by small-molecule antagonists of MDM2. Science. 2004;303:844-8.

18. Oliner JD, Pietenpol JA, Thiagalingam S, Gyuris J, Kinzler KW, Vogelstein B. Oncoprotein MDM2 conceals the activation domain of tumor suppressor p53. Nature. 1993;362:857-60.

19. Jones SN, Hancock AR, Vogel H, Donehower LA, Bradley A. Overexpression of $\mathrm{Mdm} 2$ in mice reveals a $\mathrm{p} 53$-independent role for Mdm2 in tumorigenesis. Proc Natl Acad Sci USA. 1998;95: $15608-12$.

20. Xiao ZX, Chen J, Levine AJ, Modjtahedi N, Xing J, Sellers WR, et al. Interaction between the retinoblastoma protein and the oncoprotein MDM2. Nature. 1995;375:694-8.

21. Kong Z, Deng T, Zhang M, Zhao Z, Liu Y, Luo L, et al. $\beta$ arrestin1-medieated inhibition of FOXO3a contributes to prostate cancer cell growth in vitro and in vivo. Cancer Sci. 2018;109: 1834-42.

22. Araki S, Eitel JA, Batuello CN, Bijangi-Vishehsaraei K, Xie XJ, Danielpour D, et al. TGF-beta1-induced expression of human $\mathrm{Mdm} 2$ correlates with late-stage metastatic breast cancer. J Clin Invest. 2010;120:290-302.

23. Bond GL, Hirshfield KM, Kirchhoff T, Alexe G, Bond EE, Robins H, et al. MDM2 SNP309 accelerates tumor formation in a gender-specific and hormone-dependent manner. Cancer Res. 2006;66:5104-10.

24. Duan Y, Ma G, Huang X, D'Amore PA, Zhang F, Lei H. The clustered, regularly interspaced, short palindromic repeatsassociated endonuclease 9 (CRISPR/Cas9)-created MDM2 T309G mutation enhances vitreous-induced expression of MDM2 and proliferation and survival of cells. J Biol Chem. 2016;291: 16339-4.

25. Zhou G, Duan Y, Ma G, Wu W, Hu Z, Chen N, et al. Introduction of the MDM2 T309G mutation in primary human retinal epithelial cells enhances experimental proliferative vitreoretinopathy. Invest Ophthalmol Vis Sci. 2017;58:5361-7.

26. Doudna JA, Charpentier E. Genome editing: the new frontier of genome engineering with CRISPR-Cas9. Science. 2014;346: 1258096. 
27. Swiech L, Heidenreich M, Banerjee A, Habib N, Li Y, Trombetta $\mathrm{J}$, et al. In vivo interrogation of gene function in the mammalian brain using CRISPR-Cas9. Nat Biotechnol. 2015;33:102-6.

28. Qi LS, Larson MH, Gilbert LA, Doudna JA, Weissman JS, Arkin AP, et al. Repurposing CRISPR as an RNA-guided platform for sequencespecific control of gene expression. Cell. 2013;152:1173-83.

29. Perez-Pinera P, Kocak DD, Vockley CM, Adler AF, Kabadi AM, Polstein LR, et al. RNA-guided gene activation by CRISPR-Cas9based transcription factors. Nat Methods. 2013;10:973-6.

30. Thakore PI, D'Ippolito AM, Song L, Safi A, Shivakumar NK, Kabadi AM, et al. Highly specific epigenome editing by CRISPRCas9 repressors for silencing of distal regulatory elements. Nat Methods. 2015;12:1143-9.

31. Manfredi JJ. The Mdm2-p53 relationship evolves: Mdm2 swings both ways as an oncogene and a tumor suppressor. Genes Dev. 2010;24:1580-9.

32. Huang X, Zhou G, Wu W, Ma G, D'Amore PA, Mukai S, et al. Editing VEGFR2 blocks VEGF-induced activation of Akt and tube formation. Invest Ophthalmol Vis Sci. 2017;58:1228-36.

33. Medeiros RB, Papenfuss KJ, Hoium B, Coley K, Jadrich J, Goh SK, et al. Novel sequential ChIP and simplified basic ChIP protocols for promoter co-occupancy and target gene identification in human embryonic stem cells. BMC Biotechnol. 2009;9:59.

34. Connor TB Jr., Roberts AB, Sporn MB, Danielpour D, Dart LL, et al. Correlation of fibrosis and transforming growth factor-beta type 2 levels in eyes. J Clin Invest. 1989;83:1661-6.

35. Pennock S, Haddock LJ, Mukai S, Kazlauskas A. Vascular endothelial growth factor acts primarily via platelet-derived growth factor receptor $\alpha$ to promote proliferative vitreoretinopathy. Am J Patho. 2014;184:3052-68.

36. Lin HY, Chen YS, Wang K, Chien HW, Hsieh YH, Yang SF. Fisetin inhibits epidermal growth factor-induced migration of ARPE-19 cells by suppression of AKT activation and Sp1dependent MMP-9 expression. Mol Vis. 2017;23:900-10.

37. Pennock S, Kim LA, Kazlauskas A. Vascular endothelial cell growth factor A acts via platelet-derived growth factor receptor $\alpha$ to promote viability of cells enduring hypoxia. Mol Cell Biol. 2016;36:2314-27.

38. Lei H, Rheaume MA, Cui J, Mukai S, Maberley D, Samad A, et al. A novel function ofp53: a gatekeeper of retinal detachment. Am J Pathol. 2012;181:866-74.

39. Shi XL, Yang J, Mao N, Wu JH, Ren LF, Yang Y, et al. Nutlin-3induced redistribution of chromatin-bound IFI16 in human hepatocellular carcinoma cells in vitro is associated with p53 activation. Acta Pharmacol Sin. 2015;36:252-8.

40. Sander JD, Joung JK. CRISPR-Cas systems for editing, regulating and targeting genomes. Nat Biotechnol. 2014;32: 347-55.

41. Okada M, Kanamori M, Someya K, Nakatsukasa H, Yoshimura A. Stabilization of Foxp3 expression by CRISPR-dCas9-based epigenome editing in mouse primary $\mathrm{T}$ cells. Epigenetics Chromatin. 2017;10:24.

42. OlinerJD SaikiAY, Caenepeel S. The role of MDM2 amplification and overexpression in Tumorigenesis. Cold Spring Harb Perspect Med. 2016;6:a026336. pii

43. Wang S, Zhao Y, Aguilar A, Bernard D, Yang CY. Targeting the MDM2-p53 protein-protein interaction for new cancer therapy: progress and challenges. Cold Spring Harb Perspect Med. 2017;7: a026245.

44. Momand J, Wu HH, Dasgupta G. MDM2-master regulator of the p53 tumor suppressor protein. Gene. 2000;242:15-29.

45. Moll UM, Petrenko O. The MDM2-p53 interaction. Mol Cancer Res. 2003;1:1001-8.

46. Bougeard G, Baert-Desurmont S, Tournier I, Vasseur S, Martin C, Brugieres L, et al. Impact of the MDM2 SNP309 and p53 Arg72Pro polymorphism on age of tumour onset in Li-Fraumeni syndrome. J Med Genet. 2006;43:531-3.

47. Jin M, He S, Wörpel V, Ryan SJ, Hinton DR. Promotion of adhesion and migration of RPE cells to provisional extracellular matrices by TNF-alpha. Invest Ophthalmol Vis Sci. 2000;41: 4324-32.

48. He H, Kuriyan AE, Su CW, Mahabole M, Zhang Y, Zhu YT, et al. Inhibition of proliferation and epithelial mesenchymal transition in retinal pigment epithelial cells by heavy chain-hyaluronan/pentraxin 3. Sci Rep. 2017;7:43736.

49. He T, Guo J, Song H, Zhu H, Di X, Min H, et al. Nutlin-3, an antagonist of MDM2, enhances the radiosensitivity of esophageal squamous cancer with wild-type p53. Pathol Oncol Res. 2018;24: $75-81$.

50. Burgess A, Chia KM, Haupt S, Thomas D, Haupt Y, Lim E. Clinical overview of MDM2/X-targeted therapies. Front Oncol. 2016;6:7.

51. Thomasova D, Mulay SR, Bruns H, Anders HJ. p53-independent roles of MDM2 in NF- $\mathrm{\kappa B}$ signaling: Implications for cancer therapy, wound healing, and autoimmune diseases. Neoplasia. 2012;14:1097-101. 